\title{
Variations in modern contraceptive uptake and its correlates in South West and North East Nigeria: a comparative analysis
}

\author{
Funmilola F. Oyinlola ${ }^{1 *}$, Samson O. Bamiwuye ${ }^{1}$, Stephen A. Adebowale ${ }^{2}$, \\ Opeyemi O. Ekundayo ${ }^{3}$, Benjamin B. Ilesanmi ${ }^{1}$
}

\begin{abstract}
${ }^{1}$ Department of Demography and Social Statistics, Obafemi Awolowo University Ile-Ife, Nigeria
${ }^{2}$ Department of Epidemiology and Medical Statistics, Faculty of Public Health, College of Medicine, University of Ibadan, Ibadan, Nigeria

${ }^{3}$ Department of Psychology, Obafemi Awolowo University Ile-Ife, Nigeria
\end{abstract}

Received: 21 April 2020

Accepted: 29 May 2020

\section{*Correspondence: \\ Dr. Funmilola F. Oyinlola, \\ E-mail: foyinlola@cartafrica.org}

Copyright: (c) the author(s), publisher and licensee Medip Academy. This is an open-access article distributed under the terms of the Creative Commons Attribution Non-Commercial License, which permits unrestricted non-commercial use, distribution, and reproduction in any medium, provided the original work is properly cited.

\begin{abstract}
Background: Family planning programs are implemented specifically to address the sexual and reproductive health challenges of women of childbearing age but these interventions are yet to address regional differences in modern contraceptive usage in Nigeria. Hence, this study aimed to examine correlates of modern contraceptive uptake in South West and North Eastern, Nigeria.

Methods: A cross-sectional survey data for women aged 15-49 years was extracted from Nigeria demographic and health surveys 2018 (NDHS). Data analyses were based on a weighted sample of 10,907 (North East= 5406 and South West $=5501)$ women of reproductive age. The outcome variable was modern contraceptive use. The main explanatory variables were age, employment status, religion, Number of living children, education, and marital status. Frequency distribution, Chi-square test, and binary logistic regression were used for data analysis $(\alpha=0.05)$.

Results: The result showed the mean age of women of reproductive age in South West and North East to be 32years and 30 years respectively. More women in South West used modern contraceptive than women in North East. About 91.5\% and $75.8 \%$ of women in North East and South West respectively did not used any modern method. The result showed that, in the South West, number of living children (OR:4.06, CI: 2.794-5.921), education (OR:1.35, CI: 1.0451.754) and wealth index (OR:1.77, CI: 1.053-2.973) increased the odds of contraceptive uptake, while maternal age (OR:0.52, CI: 0.282-0.965), religion (OR:0.25, CI: 0.184-0.347) and place of residence (OR:0.68, CI: 0.504-0.916) significantly reduced the odds of modern contraceptive uptake in North East.

Conclusions: This study concludes that there are regional variations in uptake and predictors of modern contraceptives use in Nigeria. Therefore, sexual and reproductive health interventions that considers the study's significant variables should be put in place to increase uptake.
\end{abstract}

Keywords: Correlates, Modern contraceptives, Variations

\section{INTRODUCTION}

Modern contraceptive uptake is an essential tool in reducing unplanned pregnancies, abortion and deaths among women of reproductive age across the globe. ${ }^{1}$ Its usage has direct impact on women's wellness and wellbeing. Modern contraceptive uptake is said to avert an additional 67 million death yearly, its benefits also encompasses economic development, maternal and child health, improvement in women's education and empowerment. $^{2}$ In regions such as Northern Europe, Latin America, the Caribbean and Northern America the uptake of family planning is high. On the contrary in Sub-Saharan Africa, most especially in middle and west 
Africa, modern contraceptives are adopted only by $23.6 \%$ of the entire population leaving 214 million women with unmet need for family planning. ${ }^{3}$ The scenario is however worst in Nigeria where total fertility rate is 5.9 and the contraceptive prevalence rate is said to have recently reached $22.7 \%$ with variations across the regions of the country that needed to be explored for appropriate policy implementation to increase uptake. ${ }^{3}$

In Nigeria, efforts have been made to increase media campaign and community sensitization by partnering with several donors to increase the demand for modern contraceptives. This was with a view to increase modern contraceptive uptake by $36 \%$ in 2018 which was not realized as the country still have a long way to go in achieving its set goal. According to Nigeria demographic and health survey (NDHS) report for 1999, 2003. 2008 and 2013 , the trend of contraceptives prevalence was $6 \%$, $12.6 \%, 14.6 \%$ and $15 \%$ respectively. These numbers are low compared to sexual activities among sexually active women of reproductive age in the country. ${ }^{4}$ Reports also showed areas in Nigeria with least development, low literacy level, and early marriage indicates lowest contraceptive uptake. ${ }^{5}$ This is said to further deprive women who are already struggling with their health and are socio economically disadvantaged.

The attempt to reduce maternal mortality rate rests solely on family planning utilization but the choice to use have been affected by scarcely identified factors. In studies conducted on contraceptive prevalence in South West Nigeria, it was indicated that the prevalence of contraceptive was $66.3 \%$ in 2011 , though the study was based on small non-representative sample. However, it was revealed that religion and family settings is a predicting factor. ${ }^{6}$ In a recent study where many women were sampled using performance monitoring and accountability 2020 survey in Lagos and Kaduna States, the prevalence rate of contraceptive uptake was $22.3 \%$. However, the study did not do any comparative analysis across regions but found visit to health care facility as the catalyst for contraceptive uptake. ${ }^{3}$ Studies on contraceptive uptake replete in northern part of the country and shown that evidence based on regional disparity in contraceptive uptake is insufficient, it is however assumable that addressing the north-south holds certain potential to promote contraceptive use and other family planning services in the country. $5,7,8$

Nigeria contributes to the highest fertility rate in Africa, it also accounted for low use of family planning commodities in the continent. The use of family planning and the choice to use have been identified to vary across the region and predictively determines the maternal mortality in Nigeria. The reproductive health and the choices of women about family planning contribute to the wide variation in maternal mortality rates between the Northern and Southern regions of the country. Within the country, the North East accounted for the highest maternal mortality (1549 per 100,000 live births) compared to South West (165 deaths per 100,000 live births) $(9,10)$. Significant progress in increasing modern contraceptive usage is not therefore assured if regional variations gaps are not effectively addressed. Hence, the study examined variations in contraceptives uptake and individual determinants of contraceptive use across South West and North East Nigeria. This is with a view to achieving the goals of universal coverage of family planning services in the country.

\section{METHODS}

The number of children per woman (TFR) remains high in Nigeria (5.5) and within the country, there is also a wide gap among the regions. In the North East, on the average a woman has as high as 8.1 children during her reproductive life while in the South West a woman has an average of 4.0 children. ${ }^{11}$ A significant percentage of women of reproductive age in South West and North East were not using any method of family planning, this disparity spurred the interest to investigate the determinants of modern contraceptive in both regions.

\section{Data source and sample size}

The data were obtained from 2018 Nigeria demographic and health survey (NDHS). This survey was nationally representative and obtained sexual and reproductive health data on women of reproductive age (15-49 years). The dataset was downloaded from the DHS website after the procedures for permission have been strictly adhered to. The survey procedure employed a multisampling technique for data collection. A detailed description of the sampling procedure for the data collection are presented in the final report of the 2018 Nigeria and demographic and health survey (ICF and Macro International, 2019). The dataset for women aged 15-49 years contained 41821 observations. However, for this study, a weighted sample size of 10,907 sexually active women involving of 5406 and 5501 from the North East and South West respectively constituted the unit of analysis

\section{Variable descriptions}

\section{Outcome variable}

The outcome variable of the study is modern contraceptive use, classified as 1 if the woman is using any modern contraceptive method and 0 if otherwise.

\section{Explanatory variable}

The main explanatory variables are age, employment status classified as unemployed and employed, marital status grouped as never married and ever married, Religion coded as Christian, Islam, traditional and others, maternal education coded as low education and high education while Number of living children was coded 0 , $1-3,4-6,7$ or more. The individual wealth index was 
classified as poorest, poorer, middle, richer and richest and place of residence was classified as urban and rural. The region was also classified as North East and South West.

\section{Analysis approach}

Frequency and percentage were used to describe the background characteristics of the study participants. Chisquare test was used to examine the association between each of the socio-demographic characteristics of the women and modern contraceptive use. A binary logistic regression analysis was employed to examine the relationship between individual characteristics and modern contraceptive use. A multi-collinearity test was performed on the explanatory variables using the variance inflation factor (VIF). The modelling approach relied on the binary logistic regression equation due to the dichotomous nature of the classification of the outcome variable. All statistical tests were performed at $5 \%$ level of significance.

\section{RESULTS}

The descriptive analysis in Figure 1 indicated that the approximately $92 \%$ of the women who were sexually active in North East were not using modern contraceptive compared with $76 \%$ of women in the South West.

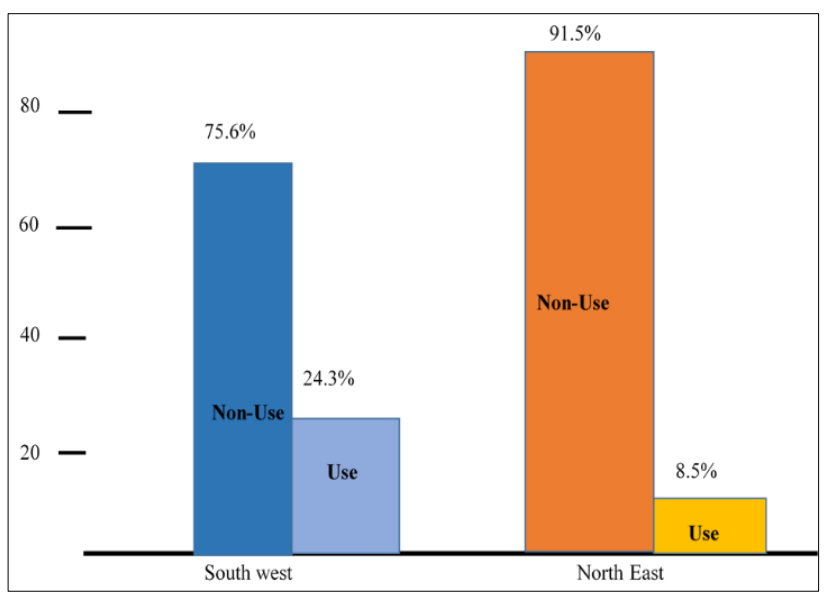

Figure 1: Contraceptive uptake in South West and North East, Nigeria.

\section{0 bivariate analysis of regional variation in maternal characteristics affecting modern contraceptive use in Nigeria}

The description of the regional variations in individual characteristics of respondents affecting the use of modern contraceptives in Nigeria was as shown in Table 1. Age as one of the important individual variables was examined to know its association with modern contraceptive uptake in both South West and North East. The Table revealed a significant association between age and modern contraceptive uptake $(2=2.99$, p-value
0.034). Contraceptive uptake is higher among women age 35-44years while many of the women in the region did not use modern contraceptive. On the other hand, in the South West, the uptake of modern contraceptive is significantly higher as compared to the North East (pvalue $<0.001$ ) across all age groups.

The number of children a woman has given birth to could serve as a justification for using family planning anywhere. In the North East, though the use of modern contraceptive is not high across all age groups, 9.6\% of women among the users with more than 4 children used modern contraceptives, the Table 1 also showed that number of living children is not a significant predictor of modern contraceptive uptake. The scenario however differs among the women in South West as number of living children significantly determined contraceptive uptake (p-value $<0.01$ with $32.6 \%$ of users having over 4 children.

Education is considered an important driver most especially in decision making. This statement is obvious among the women in North East with regards to contraceptive uptake. Though many women in this region did not use modern contraceptive but the use is more significant among women who are educated. The result showed that $94.4 \%$ of those with lower level of education were not using modern contraceptive while among the those with higher level of education, $19.2 \%$ used modern contraceptives ( $p$-value $<0.005$ ). On the contrary, despite the fact that usage is more among those with higher level of education in South West $(25.03 \%)$, there was no much difference as compared to the women with lower level of education $(22 \%)$ which is why there was no significant association between education of mothers and modern contraceptive uptake in the region as observed in North East.

Women's employment as it affects contraceptive use of women was also considered for analysis. The data indicated that the majority of the sampled women in North East either employed $(92.9 \%)$ or unemployed $(90.7 \%)$ were not using modern contraceptives while among the users the percentages are not so different and encouraging between the employed $(7.1 \%)$ and unemployed $(9.3 \%)$. However, despite the pattern of use, employment status of women in North East is a significant predictor of modern contraceptive (pvalue $<0.05)$. In the South West, employment status of women does not predict uptake. The Table indicated that there is a significant difference in contraceptive uptake of the employed $(22.03 \%)$ and the unemployed (24.6\%) with the same pattern among non-users.

Marital status is considered one of the significant predictors of contraceptive uptake in this study. In North East, the table showed that marital status significantly predicts contraceptive uptake ( $\mathrm{p}$-value $<0.001$ ). The Table showed that $12.7 \%$ of those who used modern contraceptive were not in union as only $7.9 \%$ of this 
category used modern contraceptive. On the other hand, though the variable is also a significant predictor of uptake in South West ( $\mathrm{p}$-value<0.005) but there were more users among those who are married as against the observation in North East.

Table 1: Bivariate analysis of regional variation in individual.

\begin{tabular}{|c|c|c|c|c|c|c|}
\hline \multirow[b]{2}{*}{ Variables } & \multicolumn{3}{|c|}{ North East $(\mathrm{N}=5406)$} & \multicolumn{3}{|c|}{ South West $(\mathrm{N}=\mathbf{5 5 0 1})$} \\
\hline & $\begin{array}{l}\text { Not using } n \\
(\%)\end{array}$ & $\begin{array}{l}\text { Using modern } \\
\text { method } n(\%)\end{array}$ & $\begin{array}{l}\text { Test of } \\
\text { association (2) } \\
\text { sig }\end{array}$ & $\begin{array}{l}\text { Not using } n \\
(\%)\end{array}$ & $\begin{array}{l}\text { Using modern } \\
\text { method n (\%) }\end{array}$ & $\begin{array}{l}\text { Test of } \\
\text { association } \\
\text { (2) sig }\end{array}$ \\
\hline & \multicolumn{3}{|c|}{ Contraceptive use } & \multicolumn{3}{|c|}{ Contraceptive use } \\
\hline Age (years) & & & (2.99) 0.034 & & & (9.19) 0.0002 \\
\hline $15-24$ & $1467(92.77 \%)$ & $114(7.23 \%)$ & & $869(83.87 \%)$ & $167(16.13 \%)$ & \\
\hline $25-34$ & $1846(91.26 \%)$ & $176(8.74 \%)$ & & $1599(74.23 \%)$ & $555(25.77 \%)$ & \\
\hline $35-44$ & $1180(89.64 \%)$ & $136(10.36 \%)$ & & $1203(70.51 \%)$ & $503(29.49 \%)$ & \\
\hline 45 and above & $451(93.29 \%)$ & $6(8.71 \%)$ & & $495(82.06 \%)$ & $108(17.94 \%)$ & \\
\hline \multicolumn{3}{|c|}{ Number of living children } & (1.60) 0.194 & & & $(27.84) 0.000$ \\
\hline None & $543(90.39 \%)$ & $57(9.61 \%)$ & & $857(87.73 \%)$ & $119(12.27 \%)$ & \\
\hline $1-3$ & $1858(92.41 \%)$ & $152(7.59 \%)$ & & $2163(75.94 \%)$ & $685(24.06 \%)$ & \\
\hline $4-6$ & $1436(90.43 \%)$ & $151(9.57 \%)$ & & $949(67.40 \%)$ & $459(32.60 \%)$ & \\
\hline 7 or more & $1108(91.89 \%)$ & $97(8.11 \%)$ & & $197(73.93 \%)$ & $69(26.08 \%)$ & \\
\hline Maternal education & & & (159.36) 0.000 & & & $(0.224) 1.487$ \\
\hline Lower education & $4011(94.38 \%)$ & $238(5.62 \%)$ & & $1099(78.01 \%)$ & $309(21.99 \%)$ & \\
\hline Higher education & $934(80.84 \%)$ & $221(19.16 \%)$ & & $3068(74.97 \%)$ & $1024(25.03 \%)$ & \\
\hline Occupation & & & (6.06) 0.015 & & & $(0.28) 1.129$ \\
\hline Unemployed & $1841(92.93 \%)$ & $140(7.07 \%)$ & & $578(77.97 \%)$ & $163(22.03 \%)$ & \\
\hline Employed & $3104(90.65 \%)$ & $320(9.35 \%)$ & & $3588(75.41 \%)$ & $1170(24.59 \%)$ & \\
\hline Marital status & & & (10.49) 0.001 & & & (27.07) 0.000 \\
\hline Never in union & $613(87.28 \%)$ & $89(12.72 \%)$ & & $1385(83.25 \%)$ & $278(16.75 \%)$ & \\
\hline Ever in union & $4332(92.12 \%)$ & $370(7.88 \%)$ & & $2782(72.50 \%)$ & $1055(27.50 \%)$ & \\
\hline Religion & & & (145.59) 0.000 & & & (0.39) 0.533 \\
\hline Christian & $762(78.18 \%)$ & $212(21.82 \%)$ & & $2552(76.13 \%)$ & $800(23.87 \%)$ & \\
\hline Islam & $4183(94.42 \%)$ & $247(5.58 \%)$ & & $1614(75.16 \%)$ & $533(24.84 \%)$ & \\
\hline Place of residence & & & (11.36) 0.001 & & & (17.80) 0.000 \\
\hline Urban & $1182(88.27 \%)$ & $157(11.73 \%)$ & & $3249(74.07 \%)$ & $1137(25.93 \%)$ & \\
\hline Rural & $3764(92.55 \%)$ & $303(7.45 \%)$ & & $917(82.36 \%)$ & $196(17.64 \%)$ & \\
\hline Wealth index & & & (14.16) 0.000 & & & (6.42) 0.0001 \\
\hline Poorest & $1940(95.05 \%)$ & $101(4.95 \%)$ & & $150(80.00 \%)$ & $38(20.00 \%)$ & \\
\hline Poorer & $1288(92.21 \%)$ & $108(7.79 \%)$ & & $285(86.03 \%)$ & $46(13.97 \%)$ & \\
\hline Middle & $932(90.28 \%)$ & $100(9.72 \%)$ & & $591(80.70 \%)$ & $141(19.30 \%)$ & \\
\hline Richer & $566(84.17 \%)$ & $106(15.83 \%)$ & & $1189(74.50 \%)$ & $407(25.50 \%)$ & \\
\hline Richest & $218(83.47 \%)$ & $43(16.53 \%)$ & & $1950(73.55 \%)$ & $701(26.45 \%)$ & \\
\hline
\end{tabular}

The religion of respondent which is considered the faith or believe of mothers were also taking into consideration in this study. The result showed that among the Northern women who were sampled, contraceptive uptake is higher among the Christians $(21.8 \%)$ as compared to Muslims $(5.6 \%)$ and it significantly determines the uptake in the region ( $p$-value<0.005). As observed in South West, it doesn't matter your religion, modern contraceptive uptake is not determined by the believe you practiced as a woman as the data showed that $23.9 \%$ and $24.8 \%$ of Christians and Muslims used modern contraceptives.

When authors examined place of residence in North East, it was observed that women in urban areas women used more modern contraceptive $(11.7 \%)$ than those women in rural areas of the region $(7.5 \%)$. However, place of residence determined usage of modern contraceptives ( $\mathrm{p}$ value $<0.005)$. In the same vein, contraceptive uptake is higher among urban dwellers in South West region (Pvalue $<0.005$ ) with $25.9 \%$ and $17.6 \%$ among urban and rural dwellers of the region.

Lastly on maternal characteristics as a predictor of modern contraceptive, wealth index of women was also examined. The table showed that in North East modern contraceptive uptake is higher among the richer (15.8\%) and the richest $(16.5 \%)$ as wealth index significantly predicts modern contraceptive uptake in the region $(\mathrm{p}$ - 
value $<0.005)$. Notably, modern contraceptive uptake cut across all wealth status as the richer $(25.5 \%)$ and the richest $(26.5 \%)$ practiced modern contraceptives more than the rest of the quantile with a significant association (p-value $<0.005$ ).

\section{0 multivariate analysis of regional variations in maternal characteristics affecting contraceptive use of women in Nigeria}

Considering the age of respondents in the North East, the odds of modern contraceptive uptake decreased as the age increases. This is more significant among women age 45 years and above (OR: 0.52, $\mathrm{p}<0.001)$ with the same observation among the women from the South West (OR: $0.53, \mathrm{p}<0.05)$. Further, in North East the number of living children increased the odds of using modern contraceptive.

The result showed that those with over 7 children are significantly twice likely to use modern contraceptive as compared to those with no child. In the South West, increase in number of living children increased the odds of modern contraceptive uptake (OR: 4.06, $\mathrm{p}<0.05$ ).

Maternal education showed an improvement in odds of using modern contraceptive in Nigeria. In North East, women of reproductive age with higher level of education are twice more likely to use modern contraceptive as compared to those with lower level of education (OR: $2.56, \mathrm{p}<0.05)$.

The highly educated women are also more likely to use family planning than those with lower level of education (OR: $1.35, \mathrm{p}<0.05$ ), though with lower odds as compared to Northerners. In addition, authors examined employment status at the highest level of analysis to see the consistency in association.

It is observed that being employed in the North East does not determine modern contraceptive use with the same observation among the South West respondents.

Table 2: Multivariate analysis of regional variation in correlates of modern contraceptive uptake in Nigeria.

\begin{tabular}{|c|c|c|}
\hline \multirow{2}{*}{ Variables } & \multicolumn{2}{|l|}{ South West } \\
\hline & Contraceptive use AOR (95\% CI)*** & Contraceptive use AOR $(95 \% \text { CI })^{* * * *}$ \\
\hline \multicolumn{3}{|c|}{ 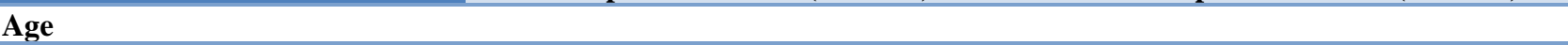 } \\
\hline $15-24$ years & $\mathrm{RC}$ & $\mathrm{RC}$ \\
\hline $25-34$ years & $0.84(0.593-1.176)$ & $1.15(0.872-1.527)$ \\
\hline $35-44$ years & $0.90(0.571-1.414)$ & $1.08(0.717-1.629)$ \\
\hline 45 years and above & $0.52(0.282-0.965) * * *$ & $0.53(0.307-1.896) * * *$ \\
\hline \multicolumn{3}{|l|}{ Living children } \\
\hline None & $\mathrm{RC}$ & $\mathrm{RC}$ \\
\hline $1-3$ & $1.09(0.739-1.614)$ & $2.11(1.566-2.867) * * *$ \\
\hline $4-6$ & $1.97(1.319-2.950) * * *$ & $4.06(2.794-5.921)^{* * *}$ \\
\hline 7 or more & $2.42(1.846-4.141) * * *$ & $3.96(2.255-6.941) * * *$ \\
\hline \multicolumn{3}{|l|}{ Maternal education } \\
\hline Lower education & $\mathrm{RC}$ & $\mathrm{RC}$ \\
\hline Higher education & $2.59(2.000-3.337)^{* * *}$ & $1.35(1.045-1.755) * * *$ \\
\hline \multicolumn{3}{|l|}{ Religion } \\
\hline Christian & $\mathrm{RC}$ & $\mathrm{RC}$ \\
\hline Islam & $0.25(0.184-0.347) * * *$ & $0.96(0.815-1.147)$ \\
\hline \multicolumn{3}{|l|}{ Employment status } \\
\hline Unemployed & $\mathrm{RC}$ & $\mathrm{RC}$ \\
\hline Employed & $0.99(0.777-1.285)$ & $0.84(0.616-1.142)$ \\
\hline \multicolumn{3}{|l|}{ Marital status } \\
\hline Never in union & $\mathrm{RC}$ & $\mathrm{RC}$ \\
\hline Ever in union & $1.19(0.856-1.669) * * *$ & $1.24(0.978-1.585)$ \\
\hline \multicolumn{3}{|l|}{ Place residence } \\
\hline Urban & $\mathrm{RC}$ & $\mathrm{RC}$ \\
\hline Rural & $0.68(0.504-0.916) * * *$ & $0.60(0.472-0.762) * * *$ \\
\hline \multicolumn{3}{|l|}{ Wealth index } \\
\hline Poorest & $\mathrm{RC}$ & $\mathrm{RC}$ \\
\hline Poorer & $1.54(1.078-2.201) * * *$ & $0.76(0.450-1.287)$ \\
\hline Middle & $1.78(1.205-2.657)^{* * *}$ & $1.21(0.685-2.158)$ \\
\hline Richer & $3.62(2.333-5.619) * * *$ & $1.77(0.035-3.012) * * *$ \\
\hline Richest & $3.78(2.278-6.294) * * *$ & $1.77(1.054-2.973) * * *$ \\
\hline
\end{tabular}


Religion of respondent shows their belief and faith of people. In this study, being a Muslim in the North East reduced the odds of using family planning (OR: 0.25 , $\mathrm{p}<0.05)$. This is explaining that the Christian adopted modern contraceptive method than the Muslim women in the North East as this situation also persisted among the women in the South West, though it is a significant predictor in later region.

As one may expect that the married women should use family planning considering the cultural background the people in Nigeria. The result showed that among the Northerner, the women who are in union have increase odds of using modern contraceptives compared to those who are not in union (OR: 1.19, p<0.05) and it significantly predicts the usage. However, in South West, though the odds increased among them but marital status does not significantly predict modern contraceptive uptake. In addition, women in rural area of North East are less likely to use modern contraceptive as compared to those in rural area and the variable is a significant predictor of modern contraceptive uptake. Similarly, the case is the same among women in South West as living in urban areas increased the odds of using modern contraceptives. Finally, at multivariate level, the wealth index of respondents shown as the wealth quantile increases the odds of usage among the women in North East with increase in variation from poorer (OR: 1.54, $\mathrm{p}<0.05)$ to richest (OR: $3.78, \mathrm{p}<0.05)$. Though the odds increased across wealth quintile in North East, the odds increase between the middle income (OR: 1.22, $\mathrm{p}<0.05$ ) to the richest (OR: 1.77, $\mathrm{p}<0.05)$ in South West area.

\section{DISCUSSION}

Several efforts have been made in improving maternal and child health through the implementation of family planning programs in Nigeria. These efforts include the free cost of family planning services, community-based interventions, and many others, despite these, it is observed that only a few are utilizing provided services of family planning and fertility remains high. Practically, the omission of women's choices or decisions in the drafting of policy for the execution of family planning services has been a major barrier to reducing unwanted pregnancy, abortion, maternal and child mortality. However, the gaps in the success of the family planning program between North East and South West have revealed the poor maternal health outcomes, and that women's choices on sexual and reproductive health decisions vary due to individual differences and regional differences. Thus, this paper addressed these issues undermining efforts by explicitly focusing on individual characteristics affecting the modern contraceptive uptake across the regions.

The findings from this study revealed that maternal age was a significant predictor of modern contraceptive uptake. This further supports the evidence from previous studies on the importance of designing friendly adolescents' sexual and reproductive services and address the unmet needs of family planning among women of advanced reproductive age. ${ }^{12-14}$ Though the results suggested a strong advocacy for all women of reproductive age in North East on modern contraceptive uptake, addressing age-specific contraceptive uptake is very important for a demographic dividend, making contraceptives available is important for the achievement of sustainable development for all women irrespective of reproductive age in the North East and Southwest.

Maternal education was further found to be significant with contraceptive uptake in both locations, with a stronger tendency most especially in Northern part of the country This implies that the educational status of women in the North East could help in understanding the patterns of contraceptive uptake and suggest programs that will enhance the ability of women in making decisions about their sexual and reproductive health outcomes. This has also been identified in previous studies that education accounted for variation in a different context, and that education remains key for women social-economic development. ${ }^{15,16}$ It also minimizes the effect of culture and traditions on women's decision on their fertility behaviour and contraceptive use within household and community at large. ${ }^{17}$ Further, women's submission and adherence to the husband's belief mostly influences women's reproductive choice. It was noted from this paper that women who were Muslims are less likely to use contraceptives when compared with women who are Christians. The variations in women's reproductive choices between North East and South West showed that being a Muslim in the North reduced the odds of using contraceptives as many of them are subjects to husband's decisions and belief with no decision autonomy compared to Christians. Not that the Christian are not subject to their spousal belief and faith in South West but being a Muslim or Christians does not just matter in using family planning and the culture and belief in the context differs. Complementarily, previous studies have also found that religion have impact on contraceptive uptake, among the Muslims compared to other religion. ${ }^{18-20}$

It was also found in previous studies that Number of living children play a significant role in shaping the plans and realization of childbearing. Though the increase in the number of living has been found in developing countries like Nigeria to be a predictor of an increase in family social capital and it is mostly viewed as an old-age investment. As a result, the inability to bear children or having a child throughout a woman's reproduction year remains culturally unacceptable in Nigeria. ${ }^{21}$ Thus, women tend to decide on their reproductive choices to eliminate stigmatization and discrimination associated with infertility hereby having more children and low contraceptive usage.

Contrary to this opinion, the study revealed contraceptive uptake in both regions increased the odds of adopting a modern contraceptive method, this is showing a paradigm 
shift in the norm within the country as studies from other context supported the findings. ${ }^{22-24}$

As against the notion that being employed is attached to more responsibility thereby controlling the fertility desires, the study showed that employment does not determine contraceptive uptake in both regions. ${ }^{25}$ The study also found marital status important in increasing uptake in Nigeria, in North East the Table 2 revealed that being in union increased the odds of contraceptive uptake this could be because the few that are using have justification for use, coupled with the fact that many of them would have add adequate number of children in their union. However, reverse is the case in South West as being in union or not does not determine uptake. The level of civilization and exposure to media and peer influence could make anyone irrespective of their marital status to use family planning, also the context differs. ${ }^{5,26}$ The finding that being in rural areas significantly reduced the odds of contraceptive uptake indicates the need put in place necessary interventions that considers place of residence in improving contraceptive uptake in Nigeria. ${ }^{27}$ Finally, wealth index increases the odds of using contraceptives in both location of study, hence the need for women empowerment to make an autonomous decision on the reproductive health. ${ }^{28,29}$

\section{CONCLUSION}

This study examined the correlates of modern contraceptive uptake focusing on the North East and South West in Nigeria. The regional model of individual characteristics associated with women's modern contraceptive uptake revealed that in the North East and South West number of living children and education and wealth index increases the odds of contraceptive uptake. In addition, for contraceptive uptake to increase factors such as age of respondent, religion and place of residence most especially in North East should be put into consideration. This study implies that, for women to use modern contraceptives special reference should be given to individual characteristics while providing interventions on the utilization of family planning services. Also, it was observed that there is a need for national policy and program on family planning to take into account the diversity in cultural and individual characteristics in each region of the country while providing family planning services. This study also calls for further support and advocacy for friendly sexual and reproductive health programs for adolescents and women of advanced reproductive age, as this will help in reducing abortion rates, improve access to health services on pregnancy complications and overall reduce maternal and child mortality in the country.

\section{ACKNOWLEDGMENTS}

Authors would like to thank department of demography and social statistics, OAU for their valuable role in actualizing this project. The authors appreciate and thanks the National Population Commission (NPC) Nigeria, ICF International and measure DHS Project for making the datasets available for use and for granting prompt authorization to analyse the data.

Funding: This research was supported by the Consortium for Advanced Research Training in Africa (CARTA). CARTA is jointly led by the African Population and Health Research Center and the University of the Witwatersrand and funded by the Carnegie Corporation of New York (Grant No--B 8606.R02), Sida (Grant No:54100113), the DELTAS Africa Initiative (Grant No: 107768/Z/15/Z) and Deutscher Akademischer Austauschdienst (DAAD). The DELTAS Africa Initiative is an independent funding scheme of the African Academy of Sciences (AAS)'s Alliance for Accelerating Excellence in Science in Africa (AESA) and supported by the New Partnership for Africa's Development Planning and Coordinating Agency (NEPAD Agency) with funding from the Wellcome Trust (UK) and the UK government. The statements made and views expressed are solely the responsibility of the fellow Conflict of interest: None declared

Ethical approval: The study was approved by the Institutional Ethics Committee

\section{REFERENCES}

1. Ameyaw EK, Budu E, Sambah F, Baatiema L, Appiah F, Seidu AA, et al. Prevalence and determinants of unintended pregnancy in sub-Saharan Africa: a multicountry analysis of demographic and health surveys. PLoS One. 2019;14(8):1-16.

2. WHO family planning/contraception. World Health Organization 2019. Available at: https://www.who.int/news-room/factsheets/detail/family-planning-contraception. Accessed on $12^{\text {th }}$ March 2020.

3. Asaolu I, Nunõ VL, Ernst K, Taren D, Ehiri J. Healthcare system indicators associated with modern contraceptive use in Ghana, Kenya, and Nigeria: evidence from the performance monitoring and accountability 2020 data. Reprod Health. 2019;16(1):110.

4. Olugbenga-Bello AI, Abodunrin OL, Adeomi AA. Contraceptive practices among women in rural communities in south-western Nigeria. Global J Med Res. 2011;11(2):1-9.

5. Wang $\mathrm{C}$, Cao H. Persisting regional disparities in modern contraceptive use and unmet need for contraception among Nigerian Women. Biomed Res Int. 2019;2019:1-9.

6. Olugbenga-Bello A, OL A, AA A. contraceptive practices among women in rural communities in SouthWestern Nigeria contraceptive practices among women in rural communities in South-Western Nigeria contraceptive practices among women in rural communities In South-Western Nigeria. Global J Med Res. 2011;11:1-8.

7. Babalola S, Oyenubi O. Factors explaining the NorthSouth differentials in contraceptive use in Nigeria: a 
nonlinear decomposition analysis. Demogr Res. 2018;38(1):287-308.

8. Gajida AU, Takai IU, Haruna IU, Bako KA. Knowledge, attitude and practice of modern contraception among women of reproductive age in urban area of kano, north-western nigeria. J Med Trop. 2019;21(2):67.

9. NPC, ICF. Nigeria demographic and health survey 2013. Natl Popul Comm. 2014;566. Available at: http://scholar.google.com/scholar?hl=en\&btnG=Search $\& q=$ intitle:Nigeria+Demographic+and+Health+Survey \#0\%5Cnhttp://scholar.google.com/scholar?hl=en\&btnG $=$ Search\&q=intitle:Nigeria+demographic+and+health+s urvey+1999\#0. Accessed on $15^{\text {th }}$ March 2020.

10. Sageer R, Kongnyuy E, Adebimpe WO, Omosehin O, Ogunsola EA, Sanni B. Causes and contributory factors of maternal mortality: Evidence from maternal and perinatal death surveillance and response in Ogun state, Southwest Nigeria. BMC Preg Childbirth. 2019;19(1):1-8.

11. National Bureau of Statistics. Demographic Statistics Bulletin Demographic Statistics, Alpacas, Sheep, and Men, (May); 2018:219-228.

12. Aransiola JO, Akinyemi AI, Fatusi AO. Women's perceptions and reflections of male partners and couple dynamics in family planning adoption in selected urban slums in Nigeria: A qualitative exploration. BMC Public Health. 2014;14(1):869.

13. Solanke BL, Oyinlola FF, Oyeleye OJ, Ilesanmi BB. Maternal and community factors associated with unmet contraceptive need among childbearing women in Northern Nigeria. Contracept Reprod Med. 2019;4(1):11.

14. Solanke BL. Advanced reproductive age and childbearing choices in Nigeria. Health Care Women Int. 2017;38(6):640-57.

15. Lesthaeghe R. The fertility transition in sub-Saharan Africa into the $21^{\text {st }}$ century. PSC Research Rep 14-823. 2014. Available at: https://pdfs.semanticscholar.org/d903/a67cfb439ce3eba 1 ca62d8cb100d92880a92.pdf. Accessed on $9^{\text {th }}$ March 2020.

16. Régnier-Loilier A, Vignoli D, Dutreuilh C. Fertility Intentions and obstacles to their realization in France and Italy. Popul. 2011;66(2):361.

17. Feyisetan BJ, Bankole A. Fertility transition in Nigeria: trends and prospect. Popul Bull UN. 2002;48(49):46178.

18. Merlo J, Wagner P, Ghith N, Leckie G. An original stepwise multilevel logistic regression analysis of discriminatory accuracy: the case of neighbourhoods and health. PloS One. 2016;(Step 1):1-31.

19. Philipov D, Berghammer C. Religion and fertility ideals, intentions and behaviour: A comparative study of European countries. Vienna Yearbook Populat Res. 2007:271-305.

20. Mishra VK, Retherford RD, Nair PS, Feeney G. Reasons for discontinuing and not intending to use contraception in India. Natl Fam Heal Surv Subj Reports Num. 13. 1999. Available at: https://scholarspace.manoa.hawaii.edu/handle/10125/34 79. Accessed on $7^{\text {th }}$ March 2020.

21. Adebowale AS, Asa S, Abe JO, Oyinlola FF. Sex preference, religion and ethnicity roles in fertility among women of childbearing age in Nigeria: examining the links using zero-inflated poisson regression model. Int J Stat Probab. 2019;8(6):91.

22. Olaolorun F, Seme A, Otupiri E, Ogunjuyigbe P, Tsui A. Women's fertility desires and contraceptive behavior in three peri-urban communities in sub Saharan Africa. Reprod Health. 2016;13(1):12.

23. Palamuleni ME. Socio-economic and demographic factors affecting contraceptive use in Malawi. 2013;17(September):91-104.

24. Choiriyyah I, Becker S. Women's covert use of contraception in 32 countries. In2017 International Population Conference 2017. IUSSP. Available at: https://iussp.confex.com/iussp/ipc2017/mediafile/Prese ntation/Paper4889/factorcovertuse.pdf. Accessed on $12^{\text {th }}$ March 2020.

25. Oladosun M, Akanbi M, Fasina F, Samuel G. Key predictors of modern contraceptive use among women in marital relationship in South-West region of Nigeria. Int J Reprod Contracept Obstet Gynecol. 2019;8(7):2638.

26. Durowade KA, Omokanye LO, Elegbede OE, Olomofe $\mathrm{CO}$, Ajiboye $\mathrm{AD}$, Makinde $\mathrm{A}$, et al. Barriers to contraceptive uptake among women of reproductive age in a semi-Urban Community of Ekiti state, Southwest Nigeria. Ethiop J Health Sci. 2017;27(2):121-8.

27. Adebowale SA, Adeoye IA, Palamuleni ME. Contraceptive use among Nigerian women with no fertility intention: Interaction amid potential causative factors. Etude la Popul Africaine. 2013;27(2):127-39.

28. Adebowale SA, Adedini SA, Ibisomi LD, Palamuleni ME. Differential effect of wealth quintile on modern contraceptive use and fertility: Evidence from Malawian women. BMC Womens Health. 2014;14(1):40.

29. OlaOlorun FM, Hindin MJ. Having a say matters: Influence of decision-making power on contraceptive use among Nigerian women ages 35-49 years. PLoS One. 2014;9(6):e98702.

Cite this article as: Oyinlola FF, Bamiwuye SO, Adebowale SA, Ekundayo OO, Ilesanmi BB. Variations in modern contraceptive uptake and its correlates in South West and North East Nigeria: a comparative analysis. Int J Reprod Contracept Obstet Gynecol 2020;9:2852-9. 